\title{
Hybrid bone SPECT/CT reveals spleen calcification in sickle cell mutation and beta-thalassemia
}

\author{
Konstantinos Sakellariou, Sofia Charalampidou, Andreas Fotopoulos ${ }^{\circ}$, Chrissa Sioka \\ Department of Nuclear Medicine, Medical School, University Hospital of loannina, Greece
}

[Received 8 IX 2021; Accepted 30 XI 2021]

\begin{abstract}
We present a case of a 65 years-old male with sickle cell mutation and beta-thalassemia ( $\mathrm{Hb} \mathrm{S} / \beta$-Thal), who had whole-body bone scan evaluation for osteomyelitis. The examination revealed high radiopharmaceutical uptake in the left abdomen. Further evaluation with hybrid single photon emission computed tomography/computed tomography (SPECT/CT) showed calcification of approximately the entire spleen, in the context of sickle cell anemia. This report highlights the role of SPECT/CT in such cases.
\end{abstract}

KEY words: sickle cell anemia; whole-body bone scan; SPECT/CT; spleen calcification

Nucl Med Rev 2022; 25, 1: 70-71

\section{Introduction}

Thalassemias denote a mixed grouping of genetic disorders that result from a decreased synthesis of alpha or beta chains of hemoglobin $(\mathrm{Hb})$. Depending on the alpha or beta hemoglobin deletion, the abnormality is called alpha or beta-thalassemia [1, 2]. Sickle cell anemia results from a mutation in the beta-globin gene that creates the abnormal $\mathrm{Hb} \mathrm{S}$ hemoglobin. Approximately 20 million people around the world are diagnosed with sickle cell anemia (SCA). In some countries, the diagnosis of sickle cell disease is performed immediately after birth, which leads to early management and relative reduction of morbidity and mortality [3]. Combination of sickle cell mutation and beta-thalassemia $(\mathrm{Hb} \mathrm{S} / \beta$-Thal) exhibits similar clinical manifestations like sickle cell disease [4].

Whole-body bone scintigraphy (BS) with Technetium-99m-methylen bisphosphonate (MDP) is a very sensitive imaging method for various reasons and in various diseases to assess bone metabolism and bone remodeling, including SCA or variant patients [5-11]. When BS demonstrates abdominal uptake in SCA patients [11], then further imaging with SPECT/CT is recommended for anatomical verification and further evaluation of the extra-osseous finding [6].

Correspondence to: Andreas Fotopoulos

Department of Nuclear Medicine, Medical School,

University Hospital of loannina, Greece

e-mail: professor.fotopoulos@yahoo.com
In this report, we present a case of a patient with $\mathrm{Hb} S / \beta$-Thal who underwent BS to rule out osteomyelitis, during which an extra-osseous radiotracer uptake was imaged in the left abdominal area, most likely representing spleen uptake. A subsequent SPECT/CT verified the spleen uptake which was due to spleen calcification.

\section{Case report}

A 65-year-old patient with known $\mathrm{Hb} S / \beta$-Thal and the subacute onset of pain in the left mandibular area was referred to Nuclear Medicine Laboratory, for a three-phase BS, to rule out possible mandibular osteomyelitis. The patient was injected with intravenous $740 \mathrm{MBq}(20 \mathrm{mCi})$ of MDP, followed by three phases of BS. During the first phase, serial scans were obtained during the first 2-5 seconds post-injection; The second phase included scans acquired 5 min post-injection that evaluated the inflammatory nature of the lesion; the third phase obtained after 3 hours assessed the bone turnover of the lesion [12]. The mandibular BS was unremarkable, since all three phases were negative, and thus, the diagnosis of osteomyelitis was ruled out. From the evaluation of the rest of the skeleton, it was observed extra-osseous mixed (moderate and high) radiotracer uptake in the left upper abdomen consisted with possible spleen uptake (Fig. 1). A hybrid SPECT/CT imaging was followed that revealed a completely calcified spleen (Fig. 2). Thus, the radiotracer uptake seen in the spleen during the BS was due to its calcification in the context of sickle cell anemia. 


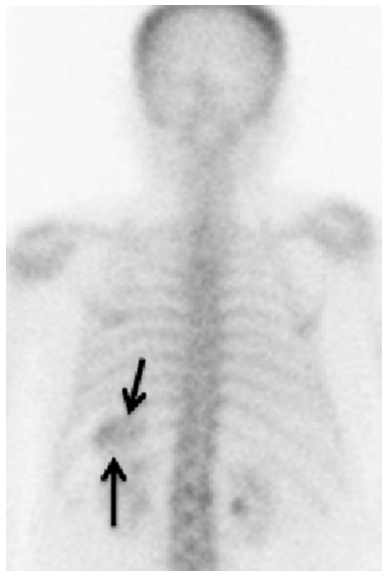

Figure 1. Posterior view in bone scintigraphy showing extra-osseous radiotracer uptake in the left upper abdomen (arrows)

\section{Discussion}

The BS is a very accurate imaging study to rule out osteomyelitis in patients with SCA or $\mathrm{Hb} S / \beta$-Thal exhibiting bone pain $[13,14]$. Increased spleen uptake of ${ }^{99 m}$ Tc-methylene diphosphonate on a BS may occur because of various conditions [11]. In patients with SCA or $\mathrm{Hb} \mathrm{S} / \beta$-Thal, BS may show increased osteoblastic activity in the skeleton due to bone marrow hyperplasia. Increased splenic uptake in patients with SCA or $\mathrm{Hb} S / \beta$-Thal, as in our case, may be due to splenic infarction followed by calcifications [10]. In such cases, further imaging with SPECT/CT improves the diagnostic accuracy and provides anatomical information [6].

In conclusion, in adult patients with SCA or $\mathrm{Hb}$ S/ $\beta$-Thal, MDP BS and SPECT/CT can identify spleen calcification possibly related to previous splenic infarction. Furthermore, in cases of not known disease, if BS reveals unusual extra-osseous radiotracer uptake, SPECT/CT should be performed, so a combination of anatomical and functional information may determine the accurate diagnosis.

\section{Conflict of interest}

None declared.

\section{References}

1. Bajwa H, Basit H. Thalassemia. Treasure Island (FL): StatPearls Publishing. 2021, indexed in Pubmed: 31424735.

2. Needs T, Gonzalez-Mosquera LF, Lynch DT. Beta-Thalassemia. Treasure Island (FL): StatPearls Publishing. 2021, indexed in Pubmed: 30285376.

3. Ashorobi D, Bhatt R. Bone marrow transplantation in sickle cell disease. Treasure Island (FL): StatPearls Publishing. 2021, indexed in Pubmed: 30860750.

4. Figueiredo MS. The compound state: $\mathrm{Hb}$ S/beta-thalassemia. Rev Bras Hematol Hemoter. 2015; 37(3): 150-152, doi: 10.1016/j.bjhh.2015.02.008, indexed in Pubmed: 26041415

5. Sioka C, Konstanti E, Papadopoulos A, et al. Heterotopic ossification in patients previously hospitalized in an intensive care unit. Nucl Med Rev Cent East Eur. 2018; 21(2): 100-103, doi: 10.5603/NMR.2018.0027, indexed in Pubmed: 30070350.

6. Niccoli Asabella A, Altini C, Nappi AG, et al. Sickle cell diseases: What can nuclear medicine offer? Hell J Nucl Med. 2019; 22(1): 2-3, doi: 10.1967/s002449910950, indexed in Pubmed: 30843001

7. Sioka C, Sakelariou K, Papoudou-Bai A, et al. Osteoblastic Solitary Plasmacytoma of Bone. Turk J Haematol. 2019; 36(2): 117-119, doi: 10.4274/tjh. galenos.2019.2018.0419, indexed in Pubmed: 30820260.

8. Fotopoulos A, Sioka C, Papadimitropoulos K, et al. Radiotherapy for breast cancer induced long-term diminished accumulation of radiotracer on bone scan of the irradiated ribs. Nucl Med Rev Cent East Eur. 2019; 22(2): 85-87, doi: 10.5603/NMR.2019.0020, indexed in Pubmed: 31482562.

9. Sioka C, Gkika E, Paliouras A, et al. Huge Abdominal Photopenic Area Due to Kidney Cyst Imaged by Bone Scintigraphy in a Prostate Cancer Patient. Clin Nucl Med. 2018; 43(11): 850-851, doi: 10.1097/RLU.0000000000002282, indexed in Pubmed: 30222683

10. Goy W, Crowe WJ. Splenic accumulation of 99mTc-diphosphonate in a patient with sickle cell disease: case report. J Nucl Med. 1976; 17(2): 108-109, indexed in Pubmed: 1245869

11. Kaur H, Muhleman M, Balon HR. Spleen Uptake on a Bone Scan. J Nucl Med Technol. 2017; 45(3): 245-246, doi: 10.2967/jnmt.117.192427, indexed in Pubmed: 28611233

12. Mavrogenis AF, Soucacos PN, Papagelopoulos PJ. Heterotopic ossification revisited. Orthopedics. 2011; 34(3): 177, doi: 10.3928/01477447-2011012408, indexed in Pubmed: 21410128.

13. Sutter CW, Shelton DK. Three-phase bone scan in osteomyelitis and other musculoskeletal disorders. Am Fam Physician. 1996; 54(5): 1639-1647, indexed in Pubmed: 8857786

14. Skaggs DL, Kim SK, Greene NW, et al. Differentiation between bone infarction and acute osteomyelitis in children with sickle-cell disease with use of sequential radionuclide bone-marrow and bone scans. J Bone Joint Surg Am. 2001; 83(12): 1810-1813, doi: 10.2106/00004623-200112000-00007, indexed in Pubmed: 11741059.
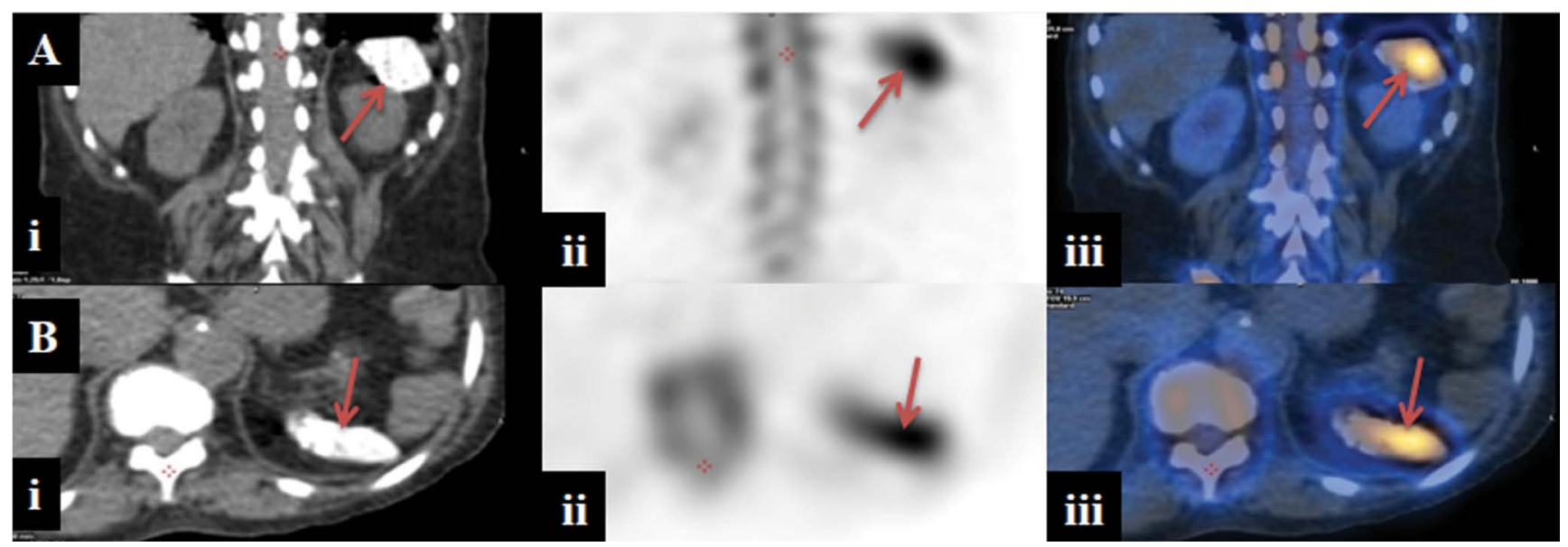

Figure 2. (A) Coronal images; (B) axial images; (i) computed tomography (CT); (ii) single photon emission computed tomography (SPECT); (iii) (SPECT/CT). Single photon emission computed tomography/computed tomography (SPECT/CT) exam confirms the radiotracer activity seen in bone scintigraphy in the left upper abdomen area showing splenic uptake (arrows) 